\title{
Isolation, screening and development of local bacterial consortia with azo dyes decolourising capability
}

\author{
Khadijah, O., ${ }^{1}$ Lee K. K. ${ }^{2}$ and Mohd Faiz F., Abdullah ${ }^{3}$ \\ ${ }^{1}$ Program Textile Technology, ${ }^{2}$ Program Applied Chemistry, ${ }^{3}$ Program Biomolecular Science, FSG, UiTM, Shah Alam. \\ E-mail:khadijah@salam.uitm.edu.my
}

Received 9 October 2008; received in revised form 15 November 2008; accepted 11 December 2008

\begin{abstract}
A total of 1540 bacterial isolates were isolated and screened for their ability to degrade selected azo dyes. Of these, nine isolates were chosen for further studies based on their ability to degrade a wide spectrum of dyes efficiently and rapidly. Several microbial consortia were developed and tested for their effectiveness. Overall the consortia were able to degrade $70-100 \%$ colour within 72 hours compared to $60-97 \%$ colour removed by individual isolates. A microbial consortium labelled $\mathrm{C} 15$ showed good growth in agitation culture but the colour removal was best in static culture with $80-100 \%$ colour removed in less than 72 hours. Based on the 16S rRNA sequencing, two of the bacterial isolates in C15 belong to the Chryseobacterium genus while the other one belongs to Flavobacterium genus.
\end{abstract}

Keywords: azo dyes, decolourisation, isolation, microbial consortia, screening

\section{INTRODUCTION}

Wastewater from textile industries creates a great pollution problem due to the dye content. The inefficiency in dyeing processes has resulted in $10-15 \%$ of unused dyestuff entering the wastewater directly (Spadarry et al., 1994). Colour present in dye effluent gives a straightforward indication of water being polluted. Major classes of synthetic dyes used include azo, anthraquinone and triarylmethane dyes and azo dyes, the largest group of all synthetic dyes represent $70 \%$ of all organic dyes used by the textile industry (Stolz, 2001). Azo dyes constitute a major class of environmental pollutants. These compounds are characterised by aromatic rings linked by an azo group, $\mathrm{N}=\mathrm{N}$. The azo linkage of azo dyes may undergo metabolic cleavage resulting in free aromatic amines which are recognised as possible human carcinogens (Banat et al., 1996). Some of the azo dyes or their breakdown products also have a strong toxic and mutagenic influence on the living organisms (Pinheiro et al., 2004). The discharge of highly coloured dye effluents can result in serious environmental damages. Thus, colour elimination in wastewater is today the principal problem concerning the textile industries since it is the first contaminant recognised in textile wastewater and has to be removed before discharging into receiving water body.

The release of azo dyes into the environment is of great concern due to colouration of natural waters and also due to toxicity, mutagenicity and carcinogenicity of the dyes and their metabolites. Considerable attention has been given in evaluating the capability of microorganisms in decolourising and degrading the azo dyes. Many studies on the decolourising capability of microorganisms especially fungi and bacteria have been reported and reviewed (Novotný et al., 2001; Kandelbauer \& Guebitz, 2005). In this study, we chose to isolate some local bacterial strains capable of decolourising selected textile dyes in wastewater. To date, although research on biodegradation of reactive azo dyes by microbial consortia have been established internationally, limited studies on the decolourising capability of bacterial strains isolated locally have been reported and their potential in wastewater treatment should therefore, be investigated.

\section{MATERIALS AND METHODS}

\section{General chemicals}

All general chemicals used were purchased from Sigma (USA), Merck (Germany) and BDH (England). Commercial test kits for the determination of some of the environmental parameters were purchased from $\mathrm{HACH}$ Company (USA). Depending upon the uses, all chemicals were of Analar, HPLC or equivalent grade.

\section{Commercial industrial dyes}

The dyes used throughout the study were reactive azo dyes obtained from the Textile Technology laboratory, Faculty of Applied Sciences, Universiti Teknologi MARA (UiTM), Shah Alam and as listed in Table 1. The reactive dyes were chosen since they are the major type of dyes that produce the greatest variety of colours and are applicable at a wide range of temperature depending upon their chemical structures. The colours of the dyes selected as the degrading indicators are the primary colours, 
namely red, blue and yellow. These primary colours are normally mixed to produce the other secondary colours. In addition violet and brown were included to widen the colour spectrum. Although the dyes have different reactive systems, the dyes are of the same chemical class and function by forming reactive bonds with the substrates. These dyes are commonly used by the local cotton and batik industries due to their ease of application and good fastness properties.

Table 1: Some information on the commercial dyes used in this study

\begin{tabular}{|c|c|c|c|c|}
\hline $\begin{array}{l}\text { Commerci } \\
\text { al name }\end{array}$ & $\begin{array}{c}\text { Generic } \\
\text { name }\end{array}$ & $\begin{array}{l}\text { Chemical } \\
\text { class }\end{array}$ & $\begin{array}{c}\text { Reactiv } \\
\text { e } \\
\text { system }\end{array}$ & $\begin{array}{l}\lambda_{\max } \\
(\mathrm{nm})\end{array}$ \\
\hline $\begin{array}{l}\text { Procion } \\
\text { Blue HERD } \\
(\mathrm{RB}-160)\end{array}$ & $\begin{array}{l}\text { C.I. } \\
\text { Reactiv } \\
\text { e Blue } \\
160\end{array}$ & azo & $\begin{array}{l}\text { copper } \\
\text { complex }\end{array}$ & 616 \\
\hline $\begin{array}{l}\text { Procion } \\
\text { Red MX-8B } \\
(\mathrm{RR}-11)\end{array}$ & $\begin{array}{l}\text { C.I. } \\
\text { Reactiv } \\
\text { e Red } \\
11\end{array}$ & azo & $\begin{array}{l}\text { monochl } \\
\text { orotriazi } \\
\text { nyl }\end{array}$ & 517 \\
\hline $\begin{array}{l}\text { Remazol } \\
\text { Red RBN } \\
\text { (RR-198) }\end{array}$ & $\begin{array}{l}\text { C.I. } \\
\text { Reactiv } \\
\text { e Red } \\
198\end{array}$ & azo & $\begin{array}{l}\text { vinylsul } \\
\text { phonyl }\end{array}$ & 545 \\
\hline $\begin{array}{l}\text { Remazol } \\
\text { Violet 5R } \\
\text { (RV-5R) }\end{array}$ & $\begin{array}{l}\text { C.I. } \\
\text { Reactiv } \\
\text { e Violet } \\
5\end{array}$ & monoazo & $\begin{array}{l}\text { vinylsul } \\
\text { phonyl }\end{array}$ & 557 \\
\hline $\begin{array}{l}\text { Proc. } \\
\text { Yellow } \\
\text { HE4R } \\
\text { (RY-84) }\end{array}$ & $\begin{array}{l}\text { C.I. } \\
\text { Reactiv } \\
\text { e Yellow } \\
84\end{array}$ & azo & $\begin{array}{l}\text { monochl } \\
\text { orotriazi } \\
\text { nyl }\end{array}$ & 400 \\
\hline $\begin{array}{l}\text { Remazol } \\
\text { Brown GR } \\
\text { (RBr-18) }\end{array}$ & $\begin{array}{l}\text { C.I. } \\
\text { Reactiv } \\
\text { e Brown } \\
18\end{array}$ & disazo & $\begin{array}{l}\text { metal } \\
\text { complex }\end{array}$ & 476 \\
\hline
\end{tabular}

\section{Decolourisation assays}

Decolourisation of the individual dyes was determined at their respective maximum absorption wavelength in the culture supernatants using a spectrophotometer (Thermo Spectronic Spectrophotometer, Genesys 20). A sample of culture broth was withdrawn daily and about $1 \mathrm{ml}$ was centrifuged at $10000 \mathrm{rpm}$ for 15 minutes (eppendorf Centrifuge 5415), before its optical density was measured. The optical densities (OD) measured were then converted to the dye concentrations using the respective standard curves. The efficiency of colour removal was expressed as the percentage ratio of the decolourised dye concentration to that of initial one based on the following equation 1 (Chen et al., 2003).

Colour removal $(\%)=\frac{\text { Dye }(i)-\text { Dye }(r)}{\text { Dye }(i)} \times 100 \%$ where Dye $(\mathrm{i})=$ initial dye concentration $(\mathrm{mg} / \mathrm{L})$, Dye $(\mathrm{r})=$ residual dye concentration $(\mathrm{mg} / \mathrm{L})$.

\section{Media and components}

Mineral salt media (E1) containing (g/l): Yeast extract (1.0), $\mathrm{NaCl}(2.0), \quad \mathrm{MgSO}_{4} \cdot 7 \mathrm{H}_{2} \mathrm{O}(0.4), \quad \mathrm{MgCl}_{2} \cdot 6 \mathrm{H}_{2} \mathrm{O}$ (0.7), $\mathrm{CaCl}_{2} \cdot 2 \mathrm{H}_{2} \mathrm{O}(0.5), \mathrm{KH}_{2} \mathrm{PO}_{4} \quad(0.3), \mathrm{K}_{2} \mathrm{HPO}_{4} \quad(0.3)$, $(\mathrm{NH} 4)_{2} \mathrm{SO}_{4}(0.5)$, and nutrient broth $(0.1)$ with $\mathrm{pH}$ adjusted to $\mathrm{pH} 7$ using $5 \mathrm{M}$ sodium hydroxide $(\mathrm{NaOH})$ and hydrochloric acid $(\mathrm{HCl})$.

\section{Bacterial isolation and cultivation}

For isolation of bacteria, water, soil and sludge samples were collected from various sources including the effluent from local textile mill, batik making site, textile laboratory, lake, streams, market, and domestic wastewater as sources for bacteria. Numerous colonies were obtained through serial dilution and/or streaking method. Isolated colonies were then obtained through serial streaking method on nutrient agar. Each strain was then inoculated into nutrient broth and incubated $24 \mathrm{~h}$ at room temperature on a platform shaker at $150 \mathrm{rpm}$ (Innova 2100, New Brunswick, Scientific). A $10 \%(\mathrm{v} / \mathrm{v})$ inoculum was transferred into $250 \mathrm{~mL}$ flask containing $100 \mathrm{~mL}$ E1 and incubated similarly. After $24 \mathrm{~h}, 10 \%(\mathrm{v} / \mathrm{v})$ samples were sub-cultured into fresh E1 media containing the respective dyes and further incubated as described above. Strains capable of utilising fresh dyes as a nutrient source were plated on E1 plates and incubated at $37^{\circ} \mathrm{C}$ for $24 \mathrm{~h}$. It was from these plates; isolated colonies were taken and repeatedly streaked on nutrient agar to obtain pure cultures. The pure bacterial cultures were subsequently transferred into nutrient broth.

\section{Screening for bacteria decolourising capability using selected azo dyes}

The bacterial isolates were cultivated in nutrient broth 24 hours before screening was done in E1 media. For initial screening, $0.1 \%(\mathrm{v} / \mathrm{v})$ aliquot of each isolated strain in nutrient broth was inoculated into a 96 well micro titre plate, each containing $200 \mu \mathrm{L}$ individual dye solutions. Decolourisation of the dye solution was monitored visually after $24 \mathrm{~h}$ incubation. Strains that showed high decolourising potential were chosen to be tested further using selected dyes incorporated in E1 agar plates.

In secondary screening using dye incorporated E1 agar plates, the selected isolates were first inoculated into the nutrient broth for $24 \mathrm{~h}$. The culture was then lawned onto the agar and left for another $24 \mathrm{~h}$ before any decolourisation zone was noted. Respective dye incorporated agars without any inoculums were used as controls and the decolourisation were estimated visually by comparing the inoculated plates with those of the control plates after 24 to $72 \mathrm{~h}$. Final screening using selected dyes in E1 liquid media were initially done using smaller volume of samples. Each selected strain was inoculated into several universal bottles containing $10 \mathrm{~mL}$ 
nutrient broth and allowed to grow for $24 \mathrm{~h}$. A sample of $10 \%(\mathrm{v} / \mathrm{v})$ of the aliquot was then transferred into some universal bottles containing $10 \mathrm{~mL}$ of $\mathrm{E} 1$ media. A final concentration of $50 \mathrm{mg} / \mathrm{l}$ of each dye was added into each bottle and the absorbance at their respective $\lambda_{\max }$ was taken initially ( $\left.t_{0}\right)$ and after a period of 24 hours $\left(t_{24}\right)$. Based on the reduction of the absorbance, the percentage of colour removal was estimated. Strains that exhibited a high potential of decolourising ability were chosen for larger scale fermentation. A sample of $10 \%(\mathrm{v} / \mathrm{v})$ of the 24 $\mathrm{h}$ bacterial culture aliquot was added to a $250 \mathrm{~mL}$ Erlenmeyer flask containing $100 \mathrm{ml}$ of $\mathrm{E} 1$ medium and 50 $\mathrm{mg} / \mathrm{L}$ dye. The shake cultures (150 rpm at ambient temperature) were grown in individual dye components or in one effluent mixture of the six dyes with total concentration maintained at $50 \mathrm{mg} / \mathrm{L}$. Uninoculated dye solutions were used as the control for the dyes. Decolourisation of the individual dyes was monitored for $72 \mathrm{~h}$ at their respective maximum absorption wavelength in culture supernatants using a spectrophotometer as described earlier.

\section{Development of bacterial consortia}

The isolates for the consortium development were selected based on three criteria; ability to degrade the dyes efficiently (>60\%), rapidly (within 3 days) and also ability to degrade a wide variety of dyes. A total of 25 consortia were developed using combinations of three to nine isolates. A loopful of the selected isolates was individually inoculated into NB for $24 \mathrm{~h}$ to form a consortium. A $10 \%(\mathrm{v} / \mathrm{v})$ aliquots of the culture mix were then transferred into a $250 \mathrm{ml}$ Erlenmeyer flask containing $100 \mathrm{ml}$ of $\mathrm{E} 1$ medium with $50 \mathrm{mg} / \mathrm{L}$ dye and allowed to react in agitated and static conditions. The decolourisation of the dye was determined as mentioned earlier. The procedure was repeated for all the dyes and also for the mixture of six dyes at equal concentrations, labelled DM.

\section{Identification of bacteria using 16S rRNA sequencing}

A 16S rRNA analysis method was used to identify the selected bacterial strains. The nearly full-length 16S RNA gene was amplified by PCR with forward primer 27F and reversed primal Universal 1492R. Purified PCR products were sequenced using the ABI PRISM 3100 DNA sequencer and the ABI PRISM BigDye Terminator Cycle Sequencing ready-reaction kit. Primers 27F, 530F, 926F, 519R, 907R and 1492R were adopted to sequence both strands of the 16S RNA gene. The sequences were finally assembled to produce the full-length sequence and the full-length sequence was compared with all other sequences available in the National Center Biotechnology Institute (NCBI) Genbank database. The probable identity of the bacterial strain was thus determined. Identification to the species level was defined as a 16S rDNA sequence similarity of $\geq 99 \%$ with that of the prototype strains in Genbank; identification at the genus level was defined as a 16S rDNA sequence similarity of $\geq 97 \%$ with that of the prototype strains in Genbank. A failure to identify was defined as a $16 \mathrm{~S}$ rDNA sequence similarity score of lower than $97 \%$ with those deposited in Genbank at the time of analysis (March, 2007) (Draincourt et al., 2000). Sequencing of the bacterial strains was conducted by Research Biolab Technologies Pte. Ltd.

\section{RESULTS AND DISCUSSION}

\section{Screening for bacteria decolourising capability using selected azo dyes}

A total of 1540 bacterial isolates were screened for decolourising capability. From the initial screening on micro titre plates, 220 isolates showed decolourising potentials and were selected for further screening in agar plates. Out of these, 37 isolates showed higher decolourising zones on dye incorporated agar plates and were chosen for the next step of screening. The 37 isolates were picked based on the higher decolourising capabilities and also their ability to degrade the majority if not all six dyes used in the study, effectively compared to the others. Final screening of the microorganisms in liquid media with incorporated dyes resulted in isolation of nine bacterial isolates capable of degrading various dyes with some isolates exhibiting capability of degrading a wide spectrum of dyes. These were tabulated in Table 2 below. Tracing back the sources of the selected isolates revealed that all these isolates were isolated from sites contaminated with textile related waste. Isolates \#84, \#85, $\# 178$ and \#188 were obtained from sand and soil near a textile printing area; isolate \#94 from soil near a cottage batik industry while isolate \#146 and \#156 were isolated from wastewater in the textile dyeing laboratory. The other two isolates, namely \#166 and \#181 were isolated from the sludge in the wastewater treatment tank of a textile finishing factory. These isolates probably have acquired natural adaptation to survive in the presence of the dyes used in the study and in the presence of minimal salt media, E1. Chen et al. (2003) and Senan and Abraham (2004) reported isolation and screening of microorganisms capable of decolourising various azo dyes from sludge samples collected from wastewater treatment sites contaminated with dyes.

Isolate \#146, \#84 and \#178 were the most efficient in degrading more than one dye with colour removal ranging $45 \%-96 \%$ depending on the dyes. RB-160 and RV-5R were the easiest dyes to degrade with RR-11 and RBr-18 being the most difficult. It should be noted that although the percentages did not reach $100 \%$, some of the liquid appeared colourless, indicating efficient decolourisation.

Among the six dyes that were used as the decolourising indicators, RB-160 and RV-5R were the easiest dyes to degrade with RR-11 and $\mathrm{RBr}-18$ being the most difficult. Some azo dyes are more resistant to removal by bacterial cells and this may be attributed to their structural differences. Both RB-160 and RV-5R are simple monoazo dyes with lower molecular weight in comparison to the other dyes thus, these two dyes were degraded more readily than others dye, which supports the earlier findings by $\mathrm{Hu}$ (2001). Zimmermann et al. 
(1982), reported similar observation while investigating the degradability of different structures of azo dyes using purified Orange II azoreductase, an initiating azo dye degradation enzyme.

Table 2: Results of final screening for bacteria capable of decolourising selected dyes

\begin{tabular}{|c|c|c|c|c|}
\hline $\begin{array}{l}\text { Isolate } \\
\#\end{array}$ & $\begin{array}{l}\text { Dye } \\
\text { degraded }\end{array}$ & $\begin{array}{l}\% \text { Colour } \\
\text { removal }\end{array}$ & Time take & \\
\hline \multirow[t]{5}{*}{146} & RB-160 & 84 & $<24$ & \\
\hline & RR-11 & 50 & hrs & $>$ \\
\hline & RR-198 & 93 & $72 \mathrm{hrs}$ & \\
\hline & $\mathrm{RBr}-18$ & 45 & 48 & \\
\hline & $\mathrm{DM}$ & 77 & $\begin{array}{l}\text { hrs } \\
72 \text { hrs }\end{array}$ & $>$ \\
\hline \multirow[t]{5}{*}{84} & RB-160 & 92 & $<48$ & \\
\hline & RR-198 & 95 & hrs & $>$ \\
\hline & RV-5R & 96 & $72 \mathrm{hrs}$ & \\
\hline & RY-84 & 84 & $<48 \mathrm{hrs}$ & \\
\hline & DM & 76 & $\begin{array}{l}24 \mathrm{hrs} \\
>72 \mathrm{hrs}\end{array}$ & \\
\hline \multirow[t]{5}{*}{188} & RB-160 & 91 & $<24 \mathrm{hrs}$ & \\
\hline & RV-5R & 97 & 72 & \\
\hline & RY-84 & 80 & $\mathrm{hrs}$ & $>$ \\
\hline & DM & 59 & $48 \mathrm{hrs}$ & \\
\hline & & & $72 \mathrm{hrs}$ & \\
\hline \multirow[t]{4}{*}{94} & RB-160 & 76 & $<24 \mathrm{hrs}$ & \\
\hline & RR-198 & 87 & $48 \mathrm{hrs}$ & \\
\hline & RY-84 & 83 & $48 \mathrm{hrs}$ & \\
\hline & DM & 52 & $>72 \mathrm{hrs}$ & \\
\hline \multirow[t]{4}{*}{156} & RB-160 & 77 & $<24$ & \\
\hline & RR-11 & 44 & hrs & $>$ \\
\hline & $\mathrm{RBr}-18$ & 14 & $72 \mathrm{hrs}$ & \\
\hline & DM & 44 & $\begin{array}{l}72 \mathrm{hrs} \\
>72 \mathrm{hrs}\end{array}$ & \\
\hline \multirow[t]{4}{*}{185} & RR-11 & 78 & $72 \mathrm{hrs}$ & \\
\hline & RR-198 & 86 & $48 \mathrm{hrs}$ & \\
\hline & $R V-5 R$ & 87 & $24 \mathrm{hrs}$ & \\
\hline & DM & 20 & $>72$ hrs & \\
\hline \multirow[t]{4}{*}{166} & RB-160 & 81 & $<24 \mathrm{hrs}$ & \\
\hline & RV-5R & 80 & $48 \mathrm{hrs}$ & \\
\hline & RBr-18 & 85 & $72 \mathrm{hrs}$ & \\
\hline & DM & 34 & $>72$ hrs & \\
\hline \multirow[t]{6}{*}{178} & RB-160 & 93 & $24 \mathrm{hrs}$ & \\
\hline & RR-198 & 88 & $48 \mathrm{hrs}$ & \\
\hline & $R V-5 R$ & 97 & $48 \mathrm{hrs}$ & \\
\hline & RY-84 & 80 & 48 & \\
\hline & $\mathrm{RBr}-18$ & 47 & hrs & $>$ \\
\hline & DM & 78 & $\begin{array}{l}72 \mathrm{hrs} \\
>72 \mathrm{hrs}\end{array}$ & \\
\hline \multirow[t]{2}{*}{181} & $R V-5 R$ & 90 & $48 \mathrm{hrs}$ & \\
\hline & DM & 37 & $>72 \mathrm{hrs}$ & \\
\hline
\end{tabular}

The dye degradability was also found to be dependent upon the number and position of hydroxyl and sulpho groups in proximity relative to the azo bond; a hydroxyl group in position 2 of the naphthol ring induced the reaction (Pasti-Grigsby et al., 1992), whereas sulpho groups in the ortho and para position hindered the reaction (Zimmermann et. al., 1982). In addition, dyes with simple structures and low molecular weight show higher rates of decolourisation, whereas decolourisation of highly substituted, high molecular weight dyes is more difficult (Sani \& Banerjee, 1999). However, no clear relationship can be observed between the position of the substituent in the aromatic rings from published structure of the dye and the degradation efficiency using the isolates in this study. Similar observation was obtained on the investigation of the degradability on different azo dye structures by Aeromonas hydrophila (Chen et al., 2003). The higher capabilities of isolates \#188, \#185, \#181, \#178, \#166, $\# 156, \# 146$, \#94 and \#84 to degrade all the dyes and the dye mixture, DM within $72 \mathrm{~h}$ indicate that the isolates might be capable of utilising the dyes as their carbon source.

Table 3: Combination of isolates selected in forming the consortia

\begin{tabular}{lcc}
\hline No. & $\begin{array}{c}\text { Consortium } \\
\text { number }\end{array}$ & Combination of isolates \\
\hline 1 & C1 & All 9 isolates \\
2 & C2 & $\# 84, \# 146, \# 156, \# 178, \# 188$ \\
3 & C3 & $\# 85, \# 146, \# 156, \# 178, \# 188$ \\
4 & C4 & $\# 85, \# 146, \# 178, \# 181, \# 188$ \\
5 & C5 & $\# 85, \# 146, \# 166, \# 178, \# 188$ \\
6 & C6 & $\# 85, \# 146, \# 178, \# 181, \# 188$ \\
7 & C7 & $\# 84, \# 146, \# 156, \# 188$ \\
8 & C8 & $\# 84, \# 146, \# 178, \# 188$ \\
9 & C9 & $\# 84, \# 146, \# 156, \# 178$ \\
10 & C10 & $\# 84, \# 156, \# 178, \# 188$ \\
11 & C11 & $\# 146, \# 156, \# 178, \# 188$ \\
12 & C12 & $\# 85, \# 146, \# 156, \# 188$ \\
13 & C13 & $\# 85, \# 146, \# 178, \# 188$ \\
14 & C14 & $\# 85, \# 156, \# 178, \# 188$ \\
15 & C15 & $\# 84, \# 146, \# 178$ \\
16 & C16 & $\# 84, \# 146, \# 188$ \\
17 & C17 & $\# 146, \# 178, \# 188$ \\
18 & C18 & $\# 146, \# 178, \# 188$ \\
19 & C19 & $\# 84, \# 146, \# 156$ \\
20 & C20 & $\# 146, \# 156, \# 188$ \\
21 & C21 & $\# 84, \# 156, \# 188$ \\
22 & C22 & $\# 84, \# 178, \# 188$ \\
23 & C23 & $\# 156, \# 178, \# 178$ \\
24 & C24 & $\# 84, \# 156, \# 178$ \\
25 & C25 & $\# 85, \# 146, \# 178$ \\
\hline
\end{tabular}

\section{Development of bacterial consortia}

Many researchers have mentioned that a higher degree of biodegradation and mineralisation can be expected when co-metabolic activities within a microbial community complement each other. In such a 'consortium', the organisms can act synergistically on a variety of dyes and dye mixtures. One organism may be able to cause a biotransformation of the dye, which consequently renders it more accessible to another organism that otherwise is unable to attack the dye (Nigam et al., 1996). Knapp and 
Newby (1995) reported an example of this approach using a mixed culture containing at least four distinct microbial strains for the degradation of the diazo-linked chromophore in an industrial effluent.

In this study, a total of 25 consortia were developed using combinations of three to nine isolates. A consortium based on the nine isolates labelled $\mathrm{C} 1$ was first tested for its dye degrading ability. However, only three dyes namely, RB-160, RR-198 and RV-5R were degraded up to $90 \%$ while the colour of the other dyes and dye mixture were only $40-70 \%$ removed. Further combinations consisted of $3-5$ isolates were formed and tried randomly. Initially, it was observed that the presence of isolate \#178 in some of the selected consortia improved the decolourising ability of the culture. These were observed in C2, C3 and C7 C9. Based on these observations, isolate \#178 was chosen as the primary isolate to be included in the next consortia formed and tested as listed in Table 3. Table 4 summarises the results for the tested consortia.

A combination of isolate \#84, \#146 and \#178, labelled C15 was found capable of degrading all the dyes most efficiently compared to the other consortia. The consortium showed good growth in agitation culture but the colour removal was best in static culture with 75 $100 \%$ of colour from the 4 dyes and dye mixture were removed. When tested in agitated culture, less than $26 \%$ colour was removed for all dyes. The results are showed in Figure 1 and Figure 2, respectively.

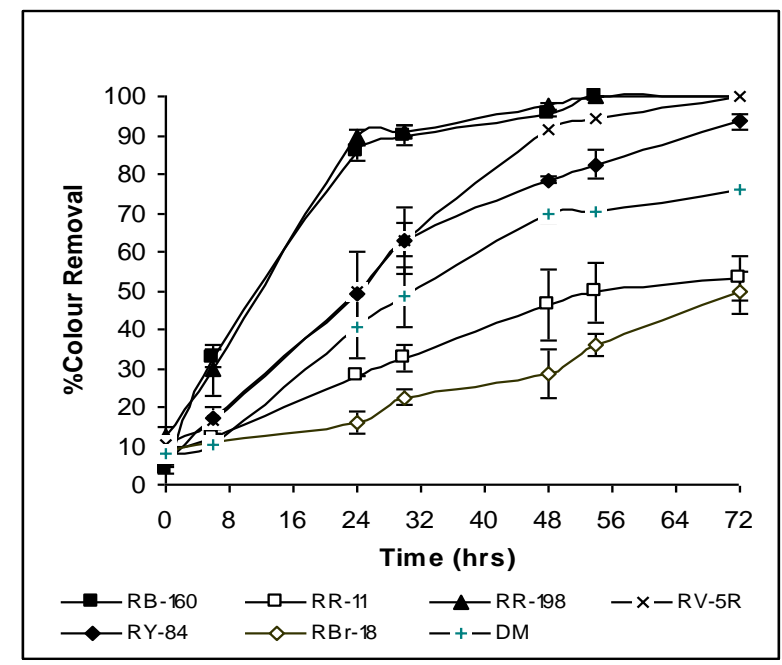

Figure 1: \% Colour removal of the dyes by $\mathrm{C} 15$ in static culture

Table 4: \% Dye decolourisation by the consortia after 72 hours inoculation

\begin{tabular}{llllllll}
\hline Consortium & \multicolumn{9}{c}{ \% De Decolourisation (after $\mathbf{7 2}$ hours) } & & & \\
& RB-160 & RR-11 & RR-198 & RV-5R & RY-84 & RBr-18 & DM \\
\hline C1 & 95 & 45 & 94 & 28 & 79 & 37 & 76 \\
C2 & 100 & 35 & 93 & 99 & 86 & 30 & 70 \\
C3 & 94 & 39 & 94 & 29 & 77 & 32 & 72 \\
C4 & 90 & 37 & 90 & 74 & 74 & 37 & 72 \\
C5 & 94 & 42 & 94 & 48 & 79 & 32 & 72 \\
C6 & 93 & 39 & 92 & 68 & 77 & 32 & 75 \\
C7 & 100 & 39 & 91 & 28 & 68 & 30 & 50 \\
C8 & 100 & 42 & 100 & 97 & 77 & 24 & 70 \\
C9 & 100 & 40 & 100 & 100 & 87 & 41 & 75 \\
C10 & 95 & 33 & 95 & 55 & 82 & 27 & 76 \\
C11 & 94 & 36 & 95 & 77 & 81 & 28 & 76 \\
C12 & 94 & 37 & 97 & 98 & 78 & 40 & 74 \\
C13 & 90 & 35 & 94 & 90 & 87 & 35 & 70 \\
C14 & 93 & 39 & 95 & 85 & 82 & 38 & 76 \\
C15 & 100 & 45 & 100 & 99 & 85 & 43 & 75 \\
C16 & 96 & 38 & 79 & 42 & 86 & 32 & 65 \\
C17 & 100 & 25 & 63 & 23 & 68 & 24 & 49 \\
C18 & 57 & 44 & 94 & 96 & 86 & 38 & 70 \\
C19 & 85 & 40 & 70 & 47 & 60 & 33 & 59 \\
C20 & 100 & 23 & 87 & 87 & 78 & 45 & 45 \\
C21 & 75 & 35 & 69 & 32 & 50 & 30 & 56 \\
C22 & 100 & 37 & 89 & 94 & 78 & 34 & 34 \\
C23 & 100 & 36 & 100 & 96 & 81 & 32 & 32 \\
C24 & 100 & 37 & 98 & 96 & 60 & 26 & 78 \\
C25 & 100 & 39 & 95 & 94 & 50 & 32 & 81 \\
\hline
\end{tabular}




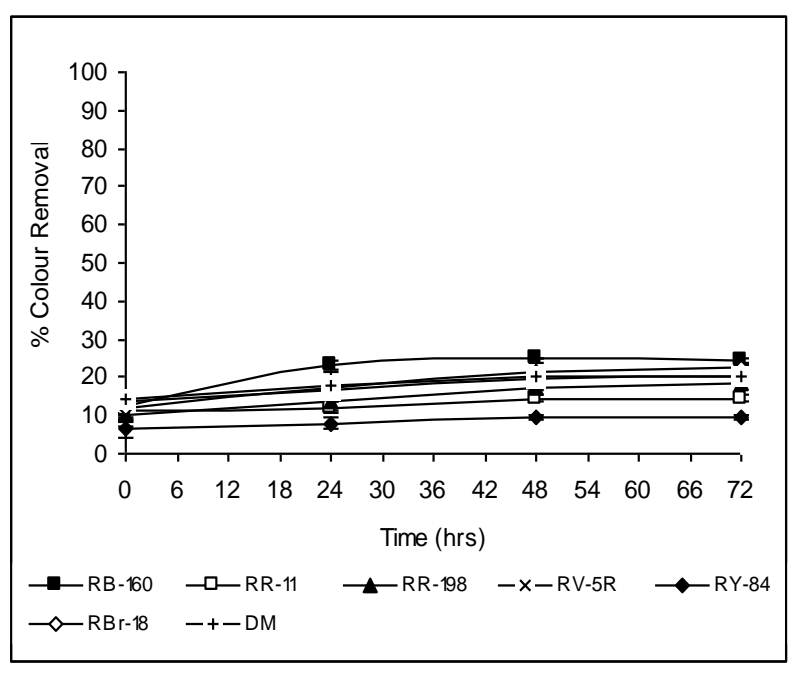

Figure 2: \% Colour removal of the dyes by $\mathrm{C} 15$ in agitated culture

These results indicate that decolourisation is not dependent on biomass concentration but is significantly correlated with dissolved oxygen levels. A similar observation was reported by Moosvi et al. (2007) where within $38 \mathrm{~h}$, maximum decolourisation of $93 \%$ was observed under static condition compared to only $24 \%$ in shaking condition. Azo dyes are quite resistant to aerobic biological degradation (Zimmermann et al., 1982); nevertheless, decolourisation in aerobic, anaerobic, anoxic, or combined treatment processes have been reported (Banat et al., 1996; Méndez-Paz et al., 2005; Khehra et al., 2005). In static incubation, transfer of oxygen is limited to the broth surface, and the cell cultures will most likely sedimented to the bottom of the flasks and become rapidly oxygen-depleted (Stolz, 2001; Chen, 2002). In the absence of oxygen, the azo dye acts as sole oxidant or electron acceptor, and its reduction rate is then governed exclusively by the rate of formation of the electron donor, in this case the reduced azo dyes (Wuhrmann et al., 1980). Although the culture was able to grow aerobically, anoxic decolourisation of the various dyes by the aerobic and facultative microbial consortium was best achieved under anaerobic conditions. Similar observations have been reported by Nigam et al. (1996), Kapdan et al. (2000), and Khehra et al. (2005). The relatively unspecific bacterial reduction under anaerobic conditions with regards to the azo compounds involved is of more use for the colour removal in dye wastewater as less energy is required for aeration and stirring. Decolourisation however, probably will not take place in extremely anaerobic conditions $\left(\mathrm{O}_{2}\right.$-free nitrogen sparging) as pointed out by Chen (2002) which indicates that a minimum amount of oxygen present in the facultative anaerobic condition (static condition) was still needed for the consortium to maintain their basic cellular activity for effective decolourisation.
The performance of consortium C15 exceeds the performance of the individual isolates with equal or more than $85 \%$ decolourisation was observed with RB-160, RR-198, RV-5R and RY-84. These results compared favourably with previous reported results (Nigam et al., 1996) showing $76 \%$ dye decolourisation in 3 days by mixed microbial consortium supplemented with cheap carbon and energy sources. All strains incubated in pure culture could reduce the colour of the dyes but the mixed culture did so more rapidly, suggesting some degree of synergism (Abraham et al., 2003). As with individual isolates, $\mathrm{RR}-11$ and $\mathrm{RBr}-18$ remained the most difficult dyes to be degraded; nevertheless the percentage of decolourisation was slightly higher than those of the individual isolates with $53 \%$ and $55 \%$ colour were removed respectively. For the dye mixture, more than $70 \%$ of colour was removed. The results show that the advantages of mixed cultures are apparent and further exploitation of the selected consortium will be beneficial in textile wastewater treatment.

\section{Identification of the bacterial isolates using 16S rRNA sequencing}

Strain \#84 and \#146, both are gram-negative bacteria, rod-shaped, motile, non-sporulating, and oxidase- and catalase-negative. Both isolates produced off-white, entire, smooth, glossy and opaque colonies on NA. The nearly full-length $16 S$ rRNA gene sequence analyses show that strains \#84 and \#146 belong to Chryseobacterium genus (gene sequence similarity value 97.9\%). Ubiquitous in nature, Chryseobacterium species are found primarily in soil and water. A novel, gramnegative, rod-shaped bacterial genus Chryseobacterium (gene sequence similarity value $<96.9 \%$ ) proposed as Chryseobacterium daeguense sp. was recently isolated by Yoon et al. (2007) from wastewater of textile dye works however, no decolourisation study was reported. Another strain identified as $C$. indologenes SB1 (gene sequence similarity value: $95.5 \%$ ) was used to form a consortium with three other species, and the consortium was able to degrade aniline and 4-chloroaniline (Radianingtyas et al., 2003). Although aniline and 4chloroaniline are closely related to dyes and dye metabolites, direct utilisation of Chryseobacterium species in decolourisation of dyes and textile wastewater were not mentioned in the literature.

Strain \#178 is also gram-negative, rod-shaped, motile, non-sporulating, and oxidase- and catalasenegative. The isolate produced golden yellow, entire, smooth, glossy and opaque colonies with smaller diameter compared to isolates \#84 and \#146 with incubation time of about 3 days at $30^{\circ} \mathrm{C}$. Incubation temperature in the region of 20 to $25{ }^{\circ} \mathrm{C}$ and incubation time of about 4 days for environmental flavobacteria were reported and most of these strains have been isolated from a variety of sources but most commonly from freshwater and marine environment (Jooste and Hugo, 1999). The $16 \mathrm{~S}$ rRNA analysis show that strain \#178 belongs to Flavobacterium genus with the closest 
relationship to Flavobacterium denitrificans (gene sequence similarity value: $96.7 \%$ ). Flavobacterium $\mathrm{sp}$. ATCC 39723 and its ability to degrade azo dye (3,5dimethyl-4-hydroxyazobenzene-4'-sulphonic acid) via a peroxidase-oxidising activity has been studied by Cao et al. (1993) however, the addition of the azo dye into the media did not enhance the enzyme production. Some Flavobacterium strains capable of degrading pentachlorophenol (PCP) were reported by Saber and Crawford (1985) however, the literature makes no mention of a Flavobacterium sp. which possesses the ability to degrade azo dyes.

The isolation of efficient dye decolourisation bacteria from the samples collected from dye contaminated soil and wastewater indicates the natural adaptation of these microorganisms to survive in the presence of the toxic dyes. Overall based on the results, the advantages of mixed cultures are apparent and further exploitation of the selected consortium will be beneficial in textile wastewater treatment.

\section{CONCLUSIONS}

Screening of the microorganisms resulted in isolation of nine bacterial isolates capable of degrading various azo dyes with some isolates exhibiting capability of degrading a wide spectrum of dyes. Consortium C15 which consisted of three potential isolates presumptively identified belonging to Chryseobacterium and Flavobacterium genus exhibited greatest ability in decolourising the dyes and the dye mixture. The performance of consortium $\mathrm{C} 15$ also exceeds the performance of the individual and the results show that the advantages of mixed cultures are apparent and further exploitation of the selected consortium will be beneficial in textile wastewater treatment.

\section{REFERENCES}

Abraham, T. E., Senan, R. C., Shaffiqu, T. S., Roy, J. J., Poulose, T. P. and Thomas, P. P. (2003). Bioremediation of textile azo dyes by an aerobic bacterial consortium using a rotating biological contactor. Biotechnology Progress 19, 1372-1376.

Banat, I. M., Nigam, P., Singh, D. and Marchant, R. (1996). Microbial decolorization of textile-dyecontaining effluents: a review. Bioresource Technology 58, 217-227.

Cao, W., Mahadevan, B., Crawford, D. L. and Crawford, R. L. (1993). Characterization of an extracellular azo dye-oxidizing peroxidase from Flavobacterium sp. ATCC 39723. Enzyme and Microbial Technology 15, 810-817.

Chen, B. Y. (2002). Understanding decolorization characteristics of reactive azo dyes by Pseudomonas luteola: toxicity and kinetics. Process Biochemistry 38, 437-446.

Chen, K., Wu, J., Liou, D. and Hwang, S. J. (2003). Decolorization of the textile dyes by newly isolated bacterial strains. Journal of Biotechnology 101, 5768.

Draincourt, M., Bollet, C., Carlioz, A., Martelin, R., Gayral, J. and Raoult, D. (2000). 16S ribosomal DNA sequence analysis of a large collection of environmental and clinical unidentifiable bacterial isolates. Journal of Clinical Microbiology 38, 36233630.

Hu, T. L. (2001). Kinetics of azoreductase and assessment of toxicity of metabolic products from azo dyes by Pseudomonas luteola. Water Science and Technology 43, 261-269.

Jooste, P. J. and Hugo, C. J. (1999). The taxonomy, ecology and cultivation of bacterial genera belonging to the family Flavobacteriaceae. International Journal of Food Microbiology 53, 81-94.

Kandelbauer, A. and Guebitz, G. M. (2005). Bioremediation for the decolorization of textile dyes a review. In Lichtfouse, E., Schwarzbauer, J. \& Robert, D. (Eds.), Environmental Chemistry - Green Chemistry and Pollutants in Ecosystem. Berlin: Springer Berlin Heidelberg.

Kapdan, I. K., Kargi, F., McMullan, G. and Marchant, R. (2000). Decolourisation of textile dyestuffs by a mixed bacterial consortium. Biotechnology Letters 22, 1179-1181.

Khehra, M. S., Saini, H. S., Sharma, D. K., Chadha, B. S. and Chimni, S. S. (2005). Comparative studies on potential of consortium and constituent pure bacterial isolates to decolorize azo dyes. Water Research 39, 5135-5141.

Knapp, J. S. and Newby, P. S. (1995). The microbiological decolorization of an industrial effluent containing a diazo-linked chromophore. Water Research 29, 1807-1809.

Méndez-Paz, D., Omil, F. and Lema, J. M. (2005). Anaerobic treatment of azo dye Acid Orange 7 under batch conditions. Enzyme and Microbial Technology 36, 364-372.

Moosvi, S., Kher, X. and Madamwar, D. (2007). Isolation, characterization of textile dyes by a mixed bacterial consortium JW-2. Dyes and Pigments 74, 723-729.

Nigam, P., Mc Mullan, G., Banat, I., \& Marchant, R. (1996). Decolourisation of effluent from the textile industry by a microbial consortium. Biotechnology Letters 18, 117-120.

Novotný, C., Rawal, B., Bhatt, M., Patel, M., Šašek, V. and Molitoris, H. P. (2001). Capacity of Irpex lacteus and Pleurotus ostreatus for decolorization of chemically different dyes. Journal of Biotechnology, 89, 113-121.

Pasti -Grigsby, M. B., Paszczynski, A., Goszynski, S., Crawford, D. L. and Crawford, R. L. (1992). Influence of aromatic substitution patterns on azo dye degradability by Streptomyces spp. and Phanerochaete chrysosporium. Applied and Environmental Microbiology 58, 3605-3613.

Pinheiro, H. M., Tourand, E. and Thomas, O. (2004). Aromatic amines from azo reduction: status review 
with emphasis on direct UV spectrophotometric detection in textile industry wastewater. Dyes and Pigment, 61, 121-139.

Radianingtyas, H., Robinson, G. K. and Bull, A. T. (2003). Characterization of a soil-derived bacterial consortium degrading 4-chloroaniline. Microbiology 149, 3279-3287.

Saber, D. E. and Crawford, R. L. (1985). Isolation and characterisation of Flavobacterium strains that degrade pentachlorophenol. Applied and Environmental Microbiology 50, 1512-1518.

Sani, R. K. and Banerjee, U. C. (1999). Decolorization of triphenylmethane dyes and textile and dye-stuff effluent by Kurthia sp. Enzyme and Microbial Technology 24, 433-437.

Senan, R. and Abraham, T. E. (2004). Bioremediation of textile azo dyes by aerobic bacterial consortium. Biodegradation 15, 275-280.

Spadarry, J. T., Isabelle, L. and Renganathan, V. (1994). Hydroxyl radical mediated degradation of azo dyes: evidence for benzene generation. Environmental Science and Technology 28, 13891393.

Stolz, A. (2001). Basic and applied aspects in the microbial degradation of azo dyes. Applied Microbiology and Biotechnology 56, 69-80.

Wuhrmann, K., Mechsner, K. and Kappeler, T. (1980). Investigation on rate-determining factors in the microbial reduction of azo dyes. European Journal of Applied Microbiology and Biotechnology 9, 325-338.

Yoon, J., Kang, S. and Oh, T. (2007). Chryseobacterium daeguense sp. Nov., isolated from wastewater of a textile dye works. International Journal of Systematic and Evolutionary Microbiology 57, 1355-1359.

Zimmermann, T., Kulla, H. G. and Leisinger, T. (1982). Properties of purified orange II azoreductase, the enzyme initiating azo dye degradation by Pseudomonas KF46. European Journal of Biochemistry 129, 197-203. 